\title{
Residual Stress in Metal-Matrix Composite Cylinder Measured by Neutron Diffraction and Contour Method
}

\author{
Vladimir Luzin ${ }^{1, a^{*}}$, Kevin Thorogood ${ }^{1, b}$, John R. Griffiths ${ }^{2, c}$, Cameron J. \\ Davidson $^{2, d}$ and Trevor R. Finlayson ${ }^{3, e}$ \\ ${ }^{1}$ Australian Nuclear Science and Technology Organisation, Locked Bag 2001, Kirrawee DC, \\ NSW, 2232 Australia \\ ${ }^{2}$ CSIRO Manufacturing, P O Box 883, Kenmore, QLD 4069, Australia \\ ${ }^{3}$ School of Physics, University of Melbourne, VIC 3100, Australia \\ a vll@ansto.gov.au, ${ }^{b}$ kjt@ansto.gov.au, ${ }^{c}$ john.griffiths@csiro.au, ${ }^{d}$ cameron.davidson@csiro.au, \\ etrevorf@unimelb.edu.au
}

Keywords: Residual Stress, Neutron Diffraction, Contour Method, Composite

\begin{abstract}
A cylindrical sample, $14.8 \mathrm{~mm}$ in diameter, was machined from an Al-Mg-Si casting and then heat-treated. For the purposes of this research, the casting can be regarded as a two-phase composite of aluminium and 6 vol.\% of near-spherical Si particles $\sim 3 \mu \mathrm{m}$ in diameter. Residual stresses in the cylinder are (i) long-range macrostresses resulting from the transient temperature gradients formed during heat-treatment, and (ii) short-range microstresses resulting from differences in the coefficients of thermal expansion between Al and Si. Neutron diffraction has been used to measure the stress tensors in each phase of the composite as a function of radial position with $2 \mathrm{~mm}$ spatial resolution and the microstress and macrostress components have been successfully separated. The contour method was applied to measure the axial component of the macrostress and the results are in good agreement with the neutron diffraction data.
\end{abstract}

\section{Introduction}

Al-Mg-Si castings are used in the aerospace and automotive industries due to their excellent castability, corrosion resistance, weldability and machinability, all combined with good mechanical properties. Typically, components are used in the heat-treated condition to achieve optimum mechanical properties.

Long-range residual stresses, or macrostresses, occur in the castings as a result of both the casting process and the subsequent heat-treatment ("long-range" means that the stresses vary over distances comparable to the size of the component). Heat-treatment comprises two steps, namely solutiontreatment and ageing. The solution-treatment comprises an anneal at $540^{\circ} \mathrm{C}$ followed by quenching into water, the resulting transient temperature gradients being responsible for long-range residual stresses. The macrostress produced through quenching usually results in a tensile core and compressive periphery, though the actual stress distribution obviously depends on the sample geometry.

Short-range residual stresses, or microstresses, are the result of differences in the coefficients of thermal expansion of the microstructural constituents of the microstructure. The stresses vary over distances comparable to the scale of the microstructure.

In the current work, one such system that produces macro- and microstress is studied: a two-phase composite of near-spherical Si particles with 6 vol.\% and $\sim 3 \mu \mathrm{m}$ in diameter in an aluminium matrix. In this paper only stresses caused by the heat-treatment are considered.

Several methods exist for the measurement of residual stress [1], each having its advantages and suitability for particular applications. Neutron diffraction is particularly suitable for measuring both the micro- and macrostresses in composite materials [2] although analysis of the data is notoriously

(c) (1) Content from this work may be used under the terms of the Creative Commons Attribution 3.0 license. Any further distribution of this work must maintain attribution to the author(s) and the title of the work, journal citation and DOI. Published under license by Materials Research Forum LLC. 
difficult, requiring the solution of the $\mathrm{d}_{0}$ problem (i.e., a knowledge of the stress-free lattice parameter of each phase of a composite), the choice of elastic constants [3] and, finally, the separation of the micro- and macrostress fields [4]. With all these experimental difficulties, a reliable alternative method is highly desirable for validation.

Although being destructive, the contour method [5] provides a straightforward means of measuring macrostresses in materials and has many advantages over other residual stress measuring techniques, including insensitivity to texture and grain size effects, chemical variations and is able to measure extremely large samples with thick cross section and complex shapes [6]. The only real limitation is the electrical resistivity of the material, which determines if the sample can be cut using the electrical discharge machining (EDM), and the spatial resolution of the technique is too coarse to measure microstress fields. Although the contour method can be applied to a variety of material types including multi-phase alloys of similar nature, e.g $\gamma / \gamma^{\prime} \mathrm{Ni}$ alloy, dual-phase steels or any other metalmetal composites, the applicability to composite materials with vastly different electrical, thermal and elastic properties, such as the Al-Si composite, can also be demonstrated.

In the current study, such an example for cross-validation between two techniques, neutron diffraction and contour method, using a cylindrical Al-Si composite sample is described.

\section{Sample and material}

The material was alloy A356, with Sr added to spheroidise the eutectic $\mathrm{Si}$ inclusions. The composition was (wt\%): $6.6 \mathrm{Si}, 0.4 \mathrm{Mg}, 0.05$ $\mathrm{Fe}, 0.18 \mathrm{Ti}, 0.019 \mathrm{Sr}$ with $\mathrm{Cu}, \mathrm{Mn}, \mathrm{Zn}$ all $<0.01$. Plates, measuring $140 \times 160 \times 25 \mathrm{~mm}^{3}$, were made by sand-casting. Slices $25 \mathrm{~mm}$ wide were cut from the plates and were solution heattreated at $540^{\circ} \mathrm{C}$ for 6 hours followed by a room-temperature water quench and ageing at $170^{\circ} \mathrm{C}$ for 6 hours. A $135 \mathrm{~mm}$ long cylindrical "dog-bone" sample was machined from one of the slices for tensile testing, with a $14.8 \mathrm{~mm}$ gauge diameter and $50 \mathrm{~mm}$ gauge length. A series of samples were produced for deformation tests, but one sample was studied in the as-heat-treated condition, with no deformation applied, therefore only thermal stresses caused by quenching and heat-treatment

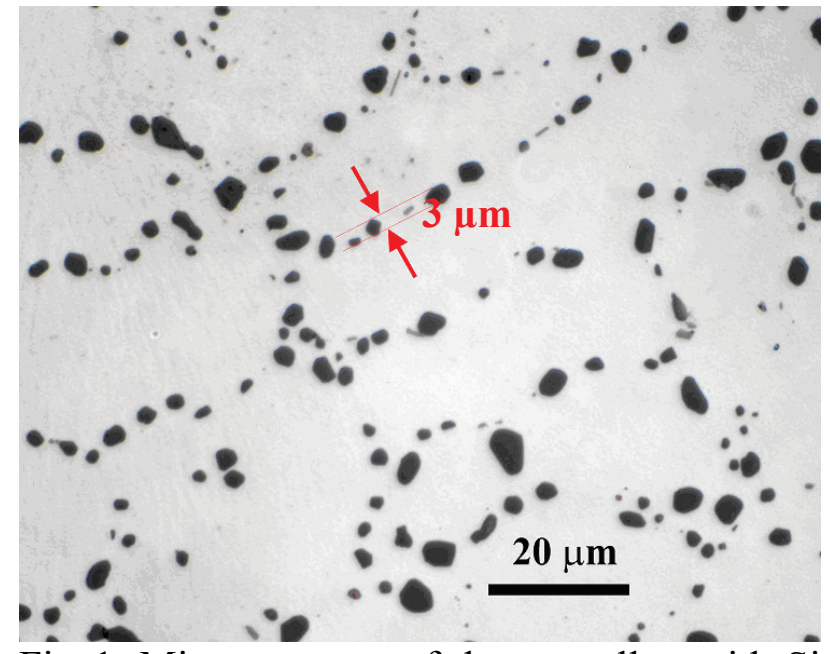

Fig. 1. Microstructure of the cast alloy with $\mathrm{Si}$ particles (dark) in the dendritic Al matrix. The arrows denote the effective thickness of the eutectic phase and the average particle diameter. exist.

The microstructure is shown in Fig.1 and has been described previously [7]. It is highly nonuniform, comprising coarse dendrite colonies (grains) some $0.8 \mathrm{~mm}$ in diameter, dendrites with a secondary dendrite arm spacing of $\sim 60 \mu \mathrm{m}$, and inter-dendritic eutectic Si inclusions with a volumeequivalent diameter $\sim 3 \mu \mathrm{m}$ and an aspect ratio of $\sim 1.6$ [8] together with age-hardening nanoprecipitates of $\mathrm{MgSi}$. The volume fraction of the $\mathrm{Si}$ inclusions is 0.062 .

\section{Experimental method I: neutron diffraction measurements and data analysis}

Neutron residual stress scanning was carried out on the KOWARI neutron diffractometer at the OPAL research reactor (ANSTO) [9]. Both phases, Al matrix and Si particles, were measured at $90^{\circ}$ geometry using wavelengths appropriate for each phase: $\lambda=1.73 \AA$ for the $\mathrm{Al}(311)$ reflection and $\lambda$ $=1.58 \AA$ to work with the $\mathrm{Si}(422)$. Three principal directions, radial, hoop and axial, were measured across the specimen diameter. A gauge volume of $2 \times 2 \times 2 \mathrm{~mm}^{3}$ was used for lattice spacing measurements in the axial direction, while, in order to utilize the geometry of the long cylindrical 
sample, the gauge volume was enlarged to $2 \times 2 \times 10 \mathrm{~mm}^{3}$ for radial and hoop measurements (the 10 $\mathrm{mm}$ dimension is parallel to the cylinder axis). Due to this difference, depending on component and phase, the measurement time was changed accordingly. A typical measurement time for hoop and radial directions was 20 minutes for $\mathrm{Si}$ and 3 minutes for Al. These times provided strain accuracy of $\sim 70 \mu$ strain for the $\mathrm{Si}(422)$ and $\sim 30 \mu$ strain for the $\mathrm{Al}(311)$.

A crucial capability of the instrument utilised for the measurements in the coarse-grained Al matrix was continuous sample rotation around the cylindrical axis to cover a physically larger sampling volume (i.e., number of grains) while keeping the same radial localization. This improves the grain statistics dramatically and yields statistically stable results. Additionally, and for the same reason, while measuring the axial component the cube gauge volume was moved in the axial direction by $10 \mathrm{~mm}$, thus sweeping the same volume as for the hoop and radial components.

To overcome the critical $\mathrm{d}_{0}$ problem associated with measuring the residual stress in a composite material, standard pure Si powder was used to measure the strain-free lattice parameter for the same reflection $\mathrm{Si}(422)$. This is a unique advantage offered by the alloy since the eutectic precipitates are pure Si. Unfortunately, the same does not apply to the Al phase: here the Al contains Si and other impurity elements in solution so that a stress-free $\mathrm{d}_{0}$ is not available. Accordingly, the aluminium $\mathrm{d}_{0}$ was assumed to be constant across the sample and was set in such a way that provided fulfilment of the macrostress balance conditions in the case of hoop and axial as well as the boundary condition for the radial component. This was achieved through performing several steps to separate micro- and macrostresses [4].

Firstly, components for the total stress of each phase, Si and Al, and each radial location $r$ were calculated from the strain in the usual way:

$$
\sigma_{i}^{p h}(r)=\frac{1}{S_{2}^{p h}}\left[\varepsilon_{i}^{p h}(r)-\left(\frac{S_{1}^{p h}}{3 S_{1}^{p h}+S_{2}^{p h}}\right)\left\{\varepsilon_{\text {hoop }}^{p h}(r)+\varepsilon_{\text {radial }}^{p h}(r)+\varepsilon_{\text {axial }}^{p h}(r)\right\}\right]
$$

where $p h$ can be Si or Al, $i$ can be "hoop", "radial" or "axial", and $S_{1}^{p h}, S_{2}^{p h}$ are the (hkl)-dependent diffraction elastic constants that were evaluated from the single crystal constants in the isotropic approximation [3]. They are reported in Table 1 together with (hkl)-dependent Young modulus, E, and Poisson ratio, $v$, that can be compared with the bulk calculated counterparts.

Table 1. Elastic properties of the composite two phases, Al and $\mathrm{Si}$

\begin{tabular}{|c|c|c|c|c|c|c|}
\hline & $S_{1}(\mathrm{hkl}), \mathrm{TPa}^{-1}$ & $S_{2}(\mathrm{hkl}), \mathrm{TPa}^{-1}$ & $E(h k l), G P a$ & $v(h k l)$ & $E$ (bulk), GPa & $v($ bulk) \\
\hline $\mathrm{Si}(422)$ & -1.285 & 7.260 & 167.4 & 0.215 & 163.1 & 0.222 \\
\hline $\mathrm{Al}(311)$ & -4.992 & 19.366 & 69.4 & 0.358 & 70.1 & 0.356 \\
\hline
\end{tabular}

Secondly, the macrostress was derived from the total phase stresses according to the volume fraction of the phases,

$$
\sigma_{i}^{M}(r)=V_{f}^{S i} \cdot \sigma_{i}^{S i}(r)+\left(1-V_{f}^{S i}\right) \cdot \sigma_{i}^{A l}(r)
$$

where $V_{f}^{S i}=0.06$ is the volume fraction of the Si particles in the composite.

Thirdly, with the calculated macrostress, the two force balance conditions, one for hoop and the other for axial components, and the boundary condition for the radial component are applied: 


$$
\int_{0}^{R} \sigma_{\text {hoop }}^{M}(r) \cdot d r=0 ; \quad \int_{0}^{R} \sigma_{\text {axial }}^{M}(r) \cdot r \cdot d r=0 ; \quad \sigma_{\text {radial }}^{M}(R)=0
$$

It is not possible to fulfil all three conditions (3) exactly, using only a single $\mathrm{d}_{0}$-value for aluminium, and so a best-estimate value was used to ensure that they comply in a statistical sense, minimising the overall error which involves all three conditions (3).

The final step was to derive the microstress for both phases:

$$
\sigma_{i}^{p h, \mu}(r)=\sigma_{i}^{p h}(r)-\sigma_{i}^{M}(r) \text {, }
$$

thus achieving separation of macrostress and microstresses.

\section{Experimental method II: contour method measurements and data analysis}

After the neutron measurements were completed, the sample was sectioned transverse to the long axis to assess the axial component of the macrostress by the contour method. Although not conducted for the purpose of this research, macrostresses in other principal directions could also be measured using the multiple-cut method [10]. The cut was made with a Sodick AQ535L wire electrical discharge machine (WEDM) with $0.25 \mathrm{~mm}$ diameter uncoated brass wire and skim cut settings. Both cut surface contours were then measured using a Brown and Sharpe Global Performance 7.10.7 co-ordinate measuring machine (CMM) at ANSTO. The machine was equipped with a Renishaw PH10M/TP200 touch probe system consisting of a $2 \mathrm{~mm}$ diameter ruby tipped stylus, with a measurement precision of $\pm 0.7 \mu \mathrm{m}$. The cut surfaces were sampled using a rotary scan method on $0.25 \mathrm{~mm}$ point spacing, producing approximately 2700 data points for each surface. The residual stresses were calculated from raw contour data using a well-proven technique consisting of MATLAB scripts and ABAQUS Finite Element code. Details of data processing methods, smoothing, fitting, etc. are reported by Prime et al. [5].

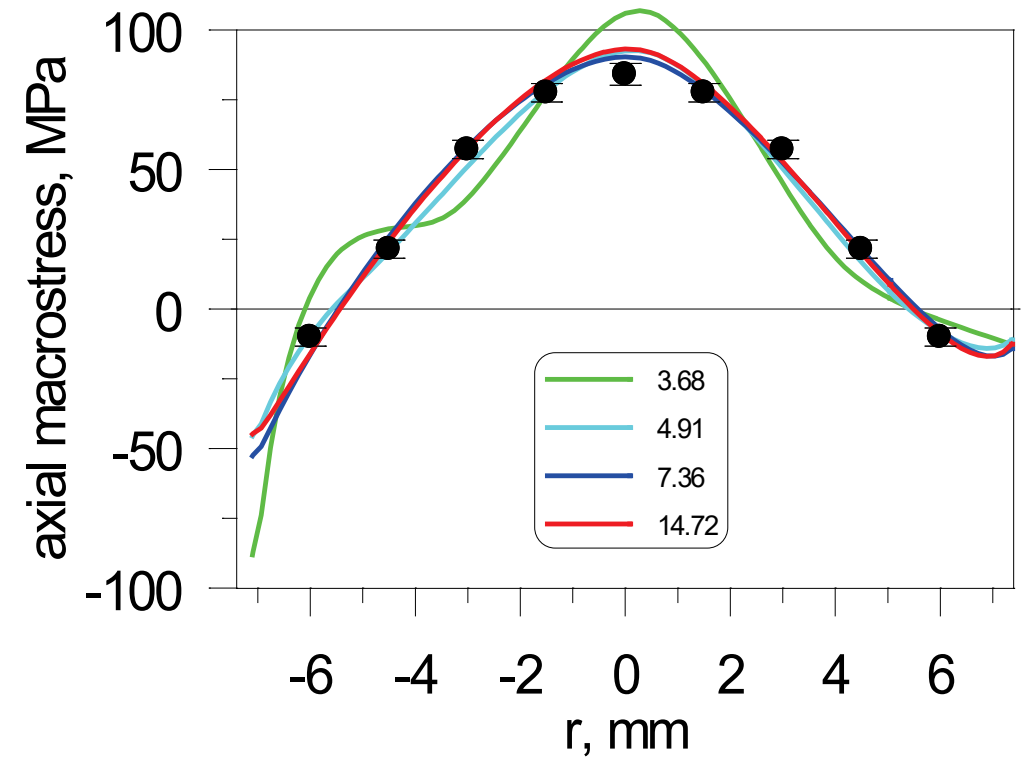

Fig. 2. Comparison of the axial component measurements obtained by neutron diffraction (symbols) and contour method (lines). Different contour method profiles correspond to the degree of smoothing (smoothing snline knot snacing narameter Imm7 is given in the legend).

\section{Results and discussion}

The comparison of data obtained by the neutron diffraction and the contour methods is shown in Fig. 2. Several profiles representing results of the contour method are distinguished by the amount of regularization (smoothing) applied in the stress reconstruction algorithm. Although apparently different, they demonstrate a quick convergence to a stably smooth solution when using a smoothing 
spline knot spacing of $\sim 5 \mathrm{~mm}$, which is in good agreement with the neutron results, $\chi^{2} \sim 2.0$. The only significant deviations from the general trend and symmetry in the contour method data are in the areas close to the perimeter and are apparently related to non-uniform EDM cutting.

While the contour method can provide a single axial macrostress component in one cut, all three principal stress components can be obtained with the neutron diffraction technique. The full set of results, three components of macro- and microstress, are shown in Fig. 3.
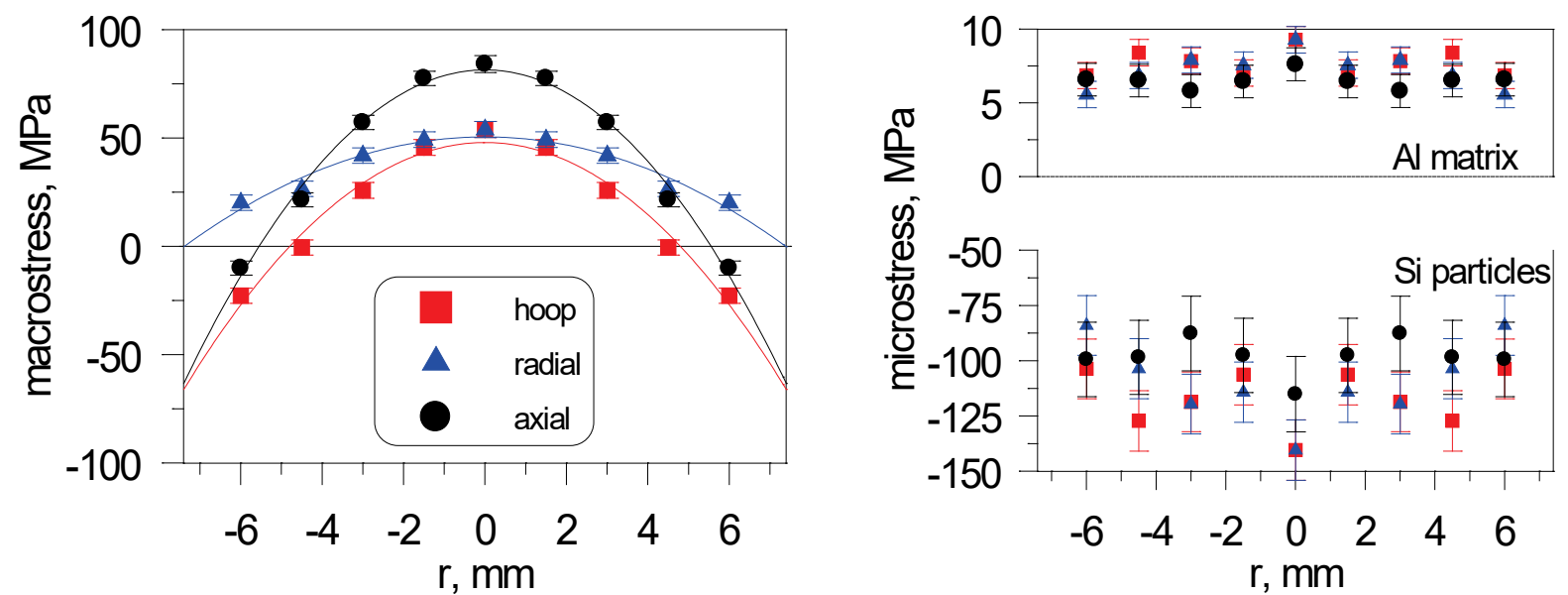

Fig. 3. Macrostress (left) and microstress (right) for the three principal stress components obtained by neutron diffraction. (The lines connecting symbols on the plot of macrostress are polynomials of the second order given for visual guidance only.)

The macrostress field shown in Fig. 3 is typical of stress fields produced by quenching although constructing a detailed anisotropic model [11] is beyond the scope of this paper. The microstress is, as expected for a composite, due to the difference in the coefficient of thermal expansion of $\mathrm{Si}$ particles and $\mathrm{Al}$ matrix. The experimentally observed hydrostatic microstress of $\sim 110 \mathrm{MPa}$ in $\mathrm{Si}$ and $\sim 7 \mathrm{MPa}$ in $\mathrm{Al}$ would be generated by cooling through a temperature of $75^{\circ} \mathrm{C}$ (evaluated by an isotropic self-consistent model [12]), which is far less than the quench from the ageing temperature of $170^{\circ} \mathrm{C}$ to ambient. Therefore, the matrix surrounding the particles must yield locally and a detailed model for the hydrostatic stress requires a knowledge of the variation of the time-temperature history and of the dependence of yield stress on temperature.

A component of the hydrostatic microstress is also caused by the macrostress field. The maximum effect is expected at the centre of the specimen where the hydrostatic macrostress is $250 \mathrm{MPa}$. Using the isotropic self-consistent model it is expected that the contribution to the microstress at the centre is $+12 \mathrm{MPa}$ for the $\mathrm{Si}$ particles and +0.8 MPa in the $\mathrm{Al}$ matrix. Thus, the macrostress-to-microstress coupling is small in comparison with the thermally generated microstress and the phase microstress values are close to the experimental error in the measurements of $\pm 13 \mathrm{MPa}$ and $\pm 0.8 \mathrm{MPa}$, respectively for $\mathrm{Si}$ and $\mathrm{Al}$. The deviatoric component of the macrostress also contributes to the microstress producing non-hydrostatic effects, that potentially can be detected, but its contribution is even smaller and certainly beyond accuracy of the current method.

\section{Summary}

Residual stress was measured in an Al-Si composite (A356 aluminium alloy) cylinder by neutron diffraction and the contour method. The cross-validation of the two methods using the axial macrostress component demonstrated a good agreement between the two methods. For the neutron diffraction technique, this ensures the proper approach to resolve the $\mathrm{d}_{0}$ problem and correct data 
treatment. For the contour method, this establishes applicability of the method to composite materials.

Using neutron diffraction data, a separation of microstress and macrostress was accomplished correctly, validated by an alternative technique. The quenching mechanism of macrostress formation was evidenced by the stress distribution and thermal mismatch between Si particles and the Al matrix and this is responsible for the microstress developed.

\section{References}

[1] M. Shokrieh, Residual Stresses in Composite Materials, Burlington: Elsevier Science, 2014.

[2] I.C. Noyan, J.B. Cohen, Residual stress: measurement by diffraction and interpretation, Springer, 1987. http://dx.doi.org/10.1007/978-1-4613-9570-6

[3] T. Gnaupel-Herold, P.C. Brand, H.J. Prask, J. Appl. Crystallogr., 31 (1998) 929-935. http://dx.doi.org/10.1107/S002188989800898X

[4] R.A. Winholtz, Separation of Microstresses and Macrostresses, in: M. Hutchings, A. Krawitz (Eds.) Measurement of Residual and Applied Stress Using Neutron Diffraction, Springer Netherlands, 1992, pp. 131-145. http://dx.doi.org/10.1007/978-94-011-2797-4_8

[5] M.B. Prime, R.J. Sebring, J.M. Edwards, D.J. Hughes, P.J. Webster, Exp. Mech., 44 (2004) 176184. http://dx.doi.org/10.1007/BF02428177

[6] M.B. Prime, A.T. DeWald, The Contour Method, in: Practical Residual Stress Measurement Methods, John Wiley \& Sons, Ltd, 2013, pp. 109-138. http://dx.doi.org/10.1002/9781118402832.ch5

[7] C.H. Caceres, C.J. Davidson, J.R. Griffiths, Q.G. Wang, Metallurgical and Materials Transactions A, 30 (1999) 2611-2618. http://dx.doi.org/10.1007/s11661-999-0301-8

[8] Q.G. Wang, C.H. Caceres, J.R. Griffiths, Metallurgical and Materials Transactions A, 34 (2003) 2901-2912. http://dx.doi.org/10.1007/s11661-003-0190-1

[9] O. Kirstein, V. Luzin, U. Garbe, Neutron News, $20 \quad$ (2009) 34-36. http://dx.doi.org/10.1080/10448630903241175

[10] P. Pagliaro, M.B. Prime, H. Swenson, B. Zuccarello, Exp. Mech., 50 (2010) 187-194. http://dx.doi.org/10.1007/s11340-009-9280-3

[11] V. Luzin, Mater. Sci. Forum, 768-769 (2014) 193-200. http://dx.doi.org/10.4028/www.scientific.net/MSF.768-769.193

[12] Z. Hashin, Journal of Applied Mechanics, 50 (1983) 481-505. http://dx.doi.org/10.1115/1.3167081 